\title{
Correction to: Risk factors for vancomycin nephrotoxicity and time course of renal function during vancomycin treatment
}

\author{
Toshinori Hirai ${ }^{1}$ (D) $\cdot$ Kazuhiko Hanada $^{2} \cdot$ Ayako Kanno $^{1} \cdot$ Megumi Akashi $^{1} \cdot$ Toshimasa Itoh $^{1}$
}

Published online: 19 March 2019

(C) Springer-Verlag GmbH Germany, part of Springer Nature 2019

Correction to: European Journal of Clinical Pharmacology https://doi.org/10.1007/s00228-019-02648-7

After online publication, we found a typographical error in Table 2. We consider correcting "VCM trough concentration $>20 \mathrm{~g} / \mathrm{mL}$ " to "VCM trough concentration $>20 \mu \mathrm{g} / \mathrm{mL}$ ".

Publisher's note Springer Nature remains neutral with regard to jurisdictional claims in published maps and institutional affiliations.

The online version of the original article can be found at https://doi.org/ 10.1007/s00228-019-02648-7

Toshinori Hirai

hirai.toshinori@twmu.ac.jp

1 Department of Pharmacy, Tokyo Women's Medical University

Medical Center East, 2-1-10, Nishiogu, Arakawa-ku,

Tokyo 116-0011, Japan

2 Department of Pharmacometrics and Pharmacokinetics, Meiji

Pharmaceutical University, 2-522-1 Noshio, Kiyose,

Tokyo 204-8588, Japan 